\title{
Review
}

Pathobiology

Pathobiology 2009;76:55-63

DOI: $\underline{10.1159 / 000201674}$

\section{Phytochemicals as Modulators of Neoplastic Phenotypes}

\author{
Heidrun Ding Sébastien Tauzin Daniel C. Hoessli \\ Department of Pathology and Immunology, Centre Medical Universitaire, Faculty of Medicine, University of \\ Geneva, Geneva, Switzerland
}

\section{Key Words}

Phytochemicals · Cancer prevention · Oncogenic addiction $\cdot$ Hormesis $\cdot$ Membrane material properties • Genome instability

\begin{abstract}
It is generally accepted that nutritional behaviors constitute decisive components of human health. Phytochemicals (small, nonenergetic molecules of vegetal origin) are overall inhibitory on the expression of gene products promoting proliferation and resistance to apoptosis. On the contrary, phytochemicals stimulate the synthesis of adaptive proteins that favor resistance to cellular stress (detoxifying and antioxidant enzymes). They are effective modulators that act synergistically on membrane, cytoplasmic and nuclear enzymatic reactions to dampen cellular hyperproliferation and hyperactivity, reequilibrate metabolic activity and promote apoptosis of genetically unstable cells. Despite important gaps in our knowledge regarding how phytochemicals interfere with cellular function in vivo, effective chemopreventive measures have shown that phytochemicals can be utilized to prevent cancer, and possibly to treat cancer patients as well. We review how phytochemicals exert their beneficial effects at the cellular level.

Copyright $\odot 2009$ S. Karger AG, Basel
\end{abstract}

\section{Introduction}

The value of nonessential, natural molecules contained in fruits and vegetables (micronutrients or phytochemicals) in maintaining health has steadily gained acceptance over the past two decades. The results of epidemiological studies on the potential benefits of fruit and vegetable diets [1], and molecular studies on the cellular effects of an extensive list of phytochemicals $[2,3]$, have generated the general awareness that molecules of vegetal origin are effective and beneficial modulators of cellular function and contribute to the prevention of cancer [4]. Representative classes of dietary bioactive molecules including terpenoids, polyphenolics, organosulfurous and alkaloid compounds are presented in table 1.

The majority of phytochemicals are also called phytoalexins, to underscore their protective role in the plant itself, for instance as insect repellents ('dietary biopesticides' $[5,6])$. When ingested by humans, subtoxic amounts of phytochemicals induce a mild adaptive stress response with heightened production of stress proteins that prepare the cell to cope with more severe adaptive challenges. This phenomenon, frequently occurring in biology and medicine, has also been termed 'preconditioning' or 'hormesis' [7]. At the cellular level, it implies that phytochemicals can interfere with and modulate signaling cellular pathways, and induce the expression of genes encoding a variety of cytoprotective and detoxifying pro-

\footnotetext{
Dr. Heidrun Ding

Centre Medical Universitaire, Department of Pathology and Immunology 1 , rue Michel-Servet

$\mathrm{CH}-1211$ Genève 4 (Switzerland)

Tel. +41 2237957 38, Fax +41 2237957 46, E-Mail heidrun.ding@unige.ch
}

\begin{tabular}{|c|c|c|}
\hline $\begin{array}{l}\text { KARGER } \\
\operatorname{Fax}+41613061234\end{array}$ & $\begin{array}{l}\text { (C) } 2009 \text { S. Karger AG, Basel } \\
1015-2008 / 09 / 0762-0055 \$ 26.00 / 0\end{array}$ & $\begin{array}{l}\text { Dr. Heidrun Ding } \\
\text { Centre Medical Universitaire, Department of Pathology and Immunology } \\
1 \text {, rue Michel-Servet }\end{array}$ \\
\hline $\begin{array}{l}\text { E-Mail karger@karger.ch } \\
\text { www.karger.com }\end{array}$ & $\begin{array}{l}\text { Accessible online at: } \\
\text { www.karger.com/pat }\end{array}$ & $\begin{array}{l}\text { CH-1211 Genève } 4 \text { (Switzerland) } \\
\text { Tel. +41 } 2237957 \text { 38, Fax +41 } 2237957 \text { 46, E-Mail heidrun.ding@unige.ch }\end{array}$ \\
\hline
\end{tabular}


Table 1. Chemical structure of the best-studied molecules of the following phytochemical groups

\begin{tabular}{|c|c|c|}
\hline Phytochemical & Plant & Molecular structure \\
\hline Curcumin & turmeric & \\
\hline Resveratrol & $\begin{array}{l}\text { (red) grapes, berries, } \\
\text { peanuts, rhubarb }\end{array}$ & \\
\hline Epicatechin & cocoa, grapes, tea, apples & \\
\hline Genistein & soybean, (chickpeas) & \\
\hline Quercetin & $\begin{array}{l}\text { onions, apples, tea, nuts, } \\
\text { berries, cauliflower, cabbage }\end{array}$ & \\
\hline Caffeic acid & $\begin{array}{l}\text { pears, basil, thyme, verbena, } \\
\text { oregano, rosemary, coffee }\end{array}$ & \\
\hline Capsaicin & red chillies & \\
\hline Lycopene & $\begin{array}{l}\text { tomatoes, watermelons, } \\
\text { guavas, pink grapefruits, } \\
\text { red oranges }\end{array}$ & \\
\hline$\beta$-Carotene & $\begin{array}{l}\text { mangos, apricots, carrots, } \\
\text { broccoli, spinach }\end{array}$ & \\
\hline Sulforaphane & $\begin{array}{l}\text { broccoli, cauliflower, } \\
\text { cabbage, kale }\end{array}$ & \\
\hline Allicin & garlic & \\
\hline
\end{tabular}

Terpenoids: carotenoid terpenoids, e.g. lycopene, $\beta$-carotene; alkaloid: e.g. capsaicin; polyphenolics: flavonoid polyphenolics, e.g. catechins, quercetin, genistein; phenolic acids, e.g. caffeic acid; other nonflavonoid polyphenolics, e.g. curcumin, resveratrol; organosulfur compounds: isothiocyanates, e.g. sulforaphane; thiosulfonates, e.g. allicin. teins. In vitro studies have identified the signaling pathways modulated by phytochemicals that regulate the activity of major transcription factors such as NFKB (nuclear factor-kappa B), FOXO (forkhead box group O) and Nrf2 (NF-E2-related factor-2), that respectively control antioxidant responses, detoxifying enzyme synthesis, energy metabolism and survival [7].
Given such effects on basic life-saving and adaptive functions, how then could phytochemicals exert an anticancer effect and selectively bring about the demise of neoplastic cells? Phytochemicals characteristically affect fundamental cellular signaling pathways by interfering with many protein or lipid kinases and transcription factors. They are essentially pleiotropic and able to inter- 
fere with pathways at different levels, not only by blocking enzymes or transcription factor binding to specific DNA response elements, but also by interfering with the membrane structure, intracytoplasmic protein-protein interactions, catalytic function of enzymes and last but not least, by interacting with DNA and promoting genome stability and integrity. As a result of such 'nonspecific' interferences, phytochemicals disorganize the aberrant signaling of neoplastic cells and may restore their apoptotic potential [4], as they are able to restore a normal activity profile in chronically active inflammatory cells [8]. In addition to their useful inhibitory effects on isolated enzymes (for instance, quercetin [9] and resveratrol [10] on PI3K (phosphatidylinositol 3'-kinase), and genistein on Src kinases [11], or piceatannol, a metabolite of resveratrol, on the Syk kinase [12]), phytochemicals like resveratrol exert their pleiotropic inhibitory effects with comparable success on neoplastic cells of different origins that most probably utilize different signaling circuits. A key survival transcription factor, such as STAT3 (signal transducer and activator of transcription-3) was efficiently inhibited by resveratrol [13] and ursolic acid [14].

One possible cause for the increased susceptibility of neoplastic and possibly other non-neoplastic (inflammatory) cells could be the signaling specialization ('oncogenic addiction') observed in epithelial $[15,16]$ and hematopoietic [17] cancer cells for one or a few oncogenic signaling proteins. With such dysregulated signaling networks strongly biased towards a limited set of signaling proteins, it is indeed understandable that phytochemicals could block prosurvival pathways more easily than in a non-neoplastic cell relying on several pathways to carry out a comparable task. Phytochemicals also influence carcinogenesis by strongly increasing the endogenous antioxidant potential [18], an enhanced capacity which is probably very effective in situations where chronic inflammation generates oxidants that pave the way for carcinogenesis [19].

The goal of this review is to discuss the anticancer effects of phytochemicals at the critical locations where signaling can be interfered with, namely (1) the plasma membrane as the site of proximal signaling, (2) the cytoplasmic signaling steps at which signalosomes are assembled and transcription factors activated, and (3) the nucleus, where activated transcription factors recognize their DNA response elements. To conclude, the important issue of how to exploit phytochemicals shall be discussed, in particular the issue of bioavailability. Most of the studies presently available have investigated in vitro

Phytochemicals as Modulators of

Neoplastic Phenotypes how phytochemicals interact with target cells. Although such studies provide invaluable information about how phytochemicals bind and modulate specific enzymes and how they chemically modify proteins and modulate redox signaling, it should be kept in mind that much remains to be learned about how phytochemicals exert their effects in vivo. Although many mouse model studies [20] and preclinical studies [21] have provided ample proof of in vivo efficacy, exactly which chemical forms of the plant molecule act on the cancer cell target and how this affects cellular functions remains to be defined.

\section{How Phytochemicals Interact with Target Cells}

The cell-modulating effects of phytochemicals shown for different cellular compartments and discussed on the following pages are summarized in figure 1.

\section{Plasma Membrane Effects}

The plasma membrane constitutes the first cellular organelle coming in contact with extracellular agonists, antagonists and toxic molecules, and contains receptors and channel proteins capable of recognizing and importing such molecules. Hydrophobic extracellular molecules could also directly interact with the membrane bilayer, and thus alter the receptors and channels that allosterically depend on their membrane lipid milieu for function [22]. This dependence of receptors and their associated cytoplasmic signaling effectors on the membrane lipids assembled in a microdomain (raft) has already been included in the concept of raft-associated signaling platforms, according to which functional signaling complexes preferentially form and function in sphingolipid-enriched and liquid-ordered plasma membrane microdomains $[23,24]$. An abundant literature has been devoted to the characterization of the interaction of phytochemicals with plasma membranes, and we shall highlight their most relevant effects on cancer cell membrane structure and function.

\section{Modulation of Membrane Material Properties}

Curcumin (diferuloylmethane) is a major bioactive compound in the turmeric spice (Curcuma longa) that especially accumulates in tumor cell membranes [25]. This accumulation in membranes causes alterations of cell shape and modulates the bilayer material properties (bilayer thickness, fluidity and elasticity) that affect 


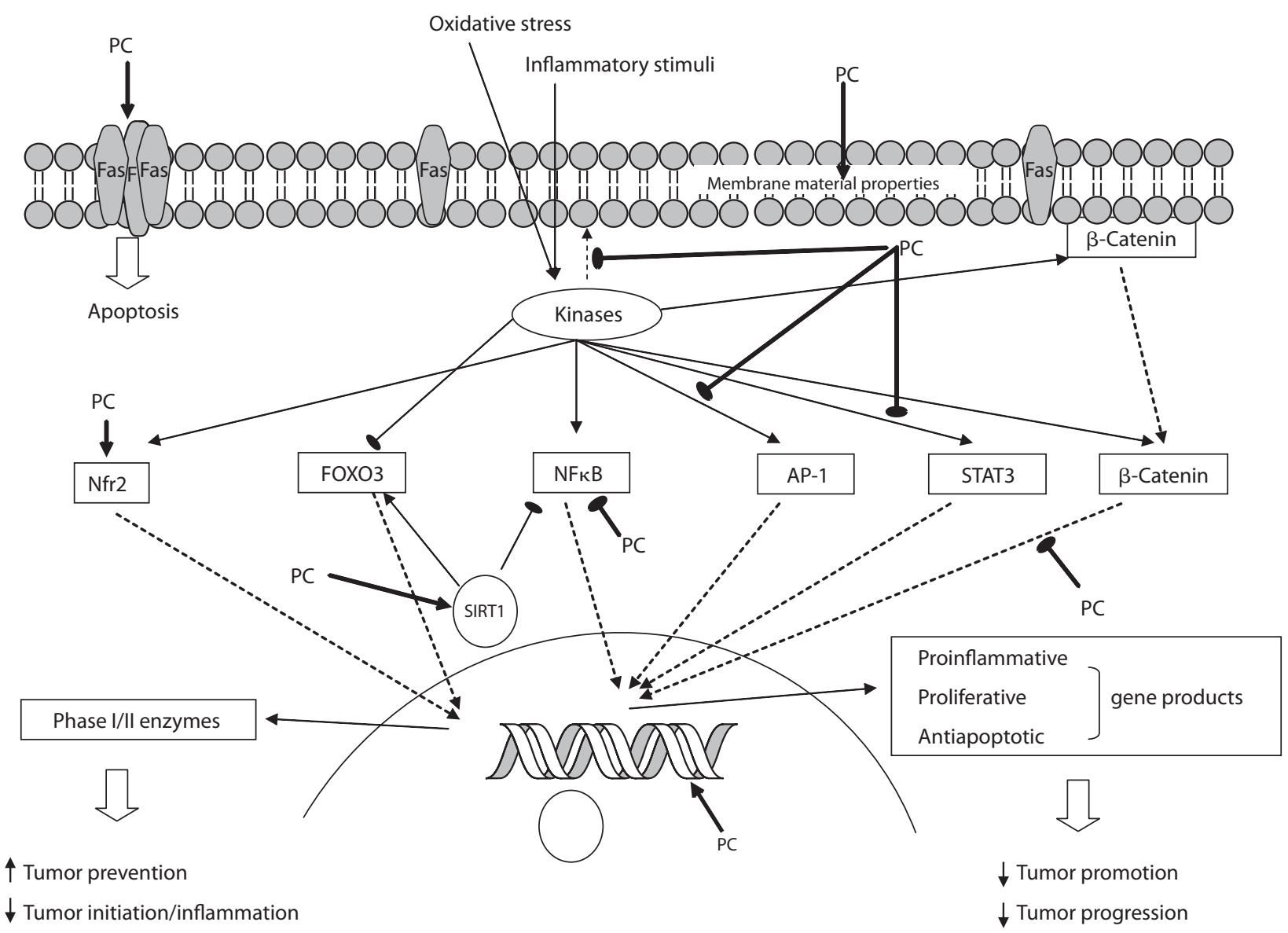

Fig. 1. Effects of phytochemicals (PC) on different signaling pathways. The activation of the transcription factors by oxidative stress or inflammatory stimuli can be direct or by kinases (e.g. PTK, PKC, PI3K/Akt, MAPK) as intermediates. The direct effects of phytochemicals are illustrated as bold lines.

membrane proteins (for instance, epidermal growth factor receptor (EGFR), multidrug resistance proteins, cystic fibrosis transmembrane conductance receptor (CFTR) and Kv1.4 potassium channels [26]). Curcumin does not target any membrane protein in particular, but rather modifies the hydrophobic coupling between membrane proteins and neighboring lipids in the membrane. In artificial bilayers, curcumin was shown to affect gramicidin single channel lifetime by causing a nonlinear membrane thinning [27]. Very similar effects have been reported for capsaicin [28] and genistein [29], and the liposomal membrane fluidity was altered in the same manner by flavonoid polyphenolics [30].

The lipophilic lycopenes and $\beta$-carotenes as well as $\mathrm{Al}$ lium organosulfurous compounds also alter the mem- brane material properties (for instance, by rigidification of the hydrophobic core of the bilayer caused by denser packing of phospholipid acyl chains and increased membrane width [31, 32]). The amphiphilic resveratrol increases membrane fluidity and may also induce relocation of the Fas receptors to rafts via interaction of its polar groups with the amino groups of the transmembrane Fas receptors $[33,34]$.

\section{Perturbation of Enzymes Associated with the Inner Membrane Leaflet}

Critical signaling proteins such as Src family kinases [35] or PI3K/Akt kinases [36] are associated with the cytoplasmic leaflet of the plasma membrane. Genistein is a Src family kinase inhibitor [11] that also modulates chan- 
nel function in a phosphorylation-independent manner, probably by dissociating Src family kinases from their optimal membrane lipid environment through rigidifying the cytoplasmic leaflet [29]. It is therefore expected that PI3K/Akt and protein kinase $\mathrm{C}$ (PKC) associations with the cytoplasmic membrane leaflet will be affected by phytochemicals that alter the physical properties of the plasma membrane, and particularly those of the inner leaflet. It could be envisaged that quercetin, by intercalating in the hydrophobic core of the bilayer, could stabilize the outer leaflet lipids in a manner analogous to cholesterol when it is embedded in sphingolipid-rich domains and liquid-ordered raft microdomains [37]. Likewise, flavonoids incorporated into erythrocyte ghost membranes increase lipid order with concomitant increases in antioxidant and antihemolytic properties [38].

Resveratrol inserts into the hydrophobic membrane core, causing for instance an inhibition of PKC association with the inner leaflet [39]. Inhibition of other inner leaflet-associated signaling kinases such as PI3K [10] and Akt are also consequences of in vitro exposure to resveratrol [40].

\section{Effects of Phytochemicals on Membrane Lipid Oxidation}

Polyphenolics are generally amphiphilic and their degree of hydrophobicity or hydrophilicity depends on the number of polar head groups. The surface-bound polyphenolics may stabilize the bilayer [41], but $\mathrm{pH}$ influences their hydrophobicity with the effect that polyphenolics of increased hydrophobicity intercalate in the lipid leaflets. For instance, quercetin was shown to become embedded in the lipid bilayers at acidic $\mathrm{pH}$, but to interact with polar hydroxyl groups at the lipid-water interface at neutral $\mathrm{pH}$ [42]. The presence of polyphenolic molecules within the bilayer, as well as the number and position of hydroxyl groups were determinant for their antioxidant potential [43]. However, it should be recalled that the much higher concentrations of small endogenous antioxidant molecules such as ascorbic acid and $\alpha$ tocopherol compared to those of most phytochemicals make the physiological relevance of an antioxidant activity displayed by phytochemicals indeed questionable [41].

The allyl derivatives from garlic decreased lipid peroxidation, probably by limiting free radical movement in the rigid membranes, and epithelial tumor cell lines exposed to 3-digit micromolar concentrations of allyl organosulfurous compounds underwent apoptosis [32].

Phytochemicals as Modulators of

Neoplastic Phenotypes

\section{Interference with Cytoplasmic Signaling}

When considering signaling proteins involved in pathways influenced by phytochemicals, it is most remarkable that all protein kinases (serine/threonine and tyrosine kinases) and related transcription factors are downregulated. One notable exception is the Nfr2 transcription factor which is activated by phytochemicals, translocates to the nucleus and increases the expression of antioxidant and detoxifying proteins [44]. In contrast, while antiapoptotic proteins are also downregulated, all the proapoptotic proteins are symmetrically upregulated [2]. These apparently coordinated responses strongly suggest that phytochemicals act upon fundamental switches of cellular activity resulting in a uniform downregulation of all pathways involved in activation responses, but a uniform upregulation of all proapoptotic genes. Different transcription factors are regulated by the cellular redox status. While Nrf2 is activated by oxidative stimuli and electrophilic carcinogens to turn on the antioxidant-detoxifying machinery, other transcription factors like $\mathrm{NF \kappa B}$ and AP-1 (activator protein 1) are activated by constantly elevated oxygen radical concentrations [44].

For curcumin, resveratrol, epigallocatechin gallate, caffeic acid phenetyl ester (CAPE) and isothiocyanates, inhibition of $\mathrm{NF} \kappa \mathrm{B}$ and $\mathrm{AP}-1$ transcription factors was reported while the nuclear translocation of Nrf2, its binding to antioxidant response elements (AREs) and the expression of detoxifying enzymes were increased [45]. For selected phytochemicals bearing an unsaturated ketone moiety (i.e. curcumin, CAPE and sulforaphane), a direct interaction of those ketone moieties with thiol groups of the Keap1 (kelch-like ECH-associated protein 1) protein has been reported. The Keapl protein that forms a complex with Nrf2 and sequesters it in the cytoplasm [46], can be modified by phytochemicals to release Nrf2 and allow its interaction with antioxidant response elements in the nucleus to enhance the expression of phase II detoxifying and antioxidant enzymes [47]. Phase I enzymes hydrolyze, reduce or oxidize substrates which are further processed by phase II transferases conjugating glucuronate, sulfate or amino acids to the metabolites to augment their water solubility.

Much of the biochemical information regarding the way in which phytochemicals inhibit kinases is still lacking, but many natural products do compete with ATP for the active site of kinases. For instance, resveratrol targets the ATP-binding site of class IA PI3K in a competitive and reversible fashion, independently of its activation of SIRT1 (sirtuin1, silent mating type information regula-

Pathobiology 2009;76:55-63 
tion 2 homolog 1) [10]. This indicates that resveratrol directly blocks PI3K and its downstream targets (in the 2digit micromolar range) and may also block other cytoplasmic kinases in a similar fashion. As a matter of fact, genistein inhibits several kinases as distinct as Akt, IKK (inhibitor of $\kappa \mathrm{B}$ kinase) and Src-family kinases, probably via competition with ATP for the kinase active site [48].

The release of Nrf2 from the complex with Keap1 is not only inducible by the oxidation of the cysteine thiol groups in Keap1 or their conformational change by covalent modifications (e.g. alkylation), but also by phosphorylation of serines and threonines of Nrf2. These effects of phosphorylation of $\mathrm{Nrf} 2$ residues are different depending on the cell type [49-51].

A recent study further suggests that isothiocyanates like sulforaphane, following their conjugation to glutathione in the enterocyte, are released as unconjugated sulforaphane in the blood (as a result of a reaction catalyzed by glutathione-S-transferase), where they convalently react with transforming growth factor beta 1 (TGFß1), epidermal growth factor (EGF) and insulin to form thioureas [52]. This reaction is favored in individuals expressing GSTM1 (glutathione S-transferase mu 1), and the thiourea-modified TGF $\beta 1$ appears to be more effective than unmodified TGF $\beta 1$ in mediating TGF $\beta 1 /$ Smad transcription. Actually, the TGF $\beta 1$ and EGF signaling pathways were enhanced in prostate biopsies from GSTM1+ individuals who followed a broccoli-rich diet [52]. The results of this study strongly suggest that consumption of isothiocyanates from broccoli causes changes in mRNA expression patterns in the prostate tissue that reflect beneficial alteration in oncogenic signaling, and point to the fact that sulforaphanes may act in the blood rather than in cells.

\section{Nuclear Effects}

The maintenance of genome integrity is achieved by an elaborate machinery of DNA repair enzymes that excise damaged DNA and synthesize new DNA to ensure the availability of undamaged genetic material [53]. The usefulness of several phytochemicals in maintaining genome integrity was recently reviewed [54] and shows that phytochemicals do far more than slowing down the process of carcinogenesis, as originally documented for resveratrol [55]. A direct interaction of resveratrol, genistein and quercetin with DNA $[56,57]$ indeed suggests that such phytochemicals may exert a protective effect directly on DNA by preventing breaks [54].
The ATM/ATR (ataxia telangiectasia mutated kinase/ ataxia telangiectasia and Rad3-related kinase) kinases are PI3K-related kinases involved in double-strand break repair, and activated by resveratrol [58]. However, there remain many unknown factors regarding the causes of ATM/ATR activation by resveratrol. Interestingly, resveratrol (but also quercetin and genistein) appear capable of activating the ATM/ATR kinases without previous DNA damage, and thus may prepare the cell to face further challenges such as those encountered in the course of cancer progression. This is indeed in line with the hormetic effects attributed to many phytochemicals [7]. Despite a number of contradictory observations, it seems probable that SIRT1 is involved in resveratrol-mediated DNA repair via the SIRT1 deacetylated substrates p53 and Nbs1 [43].

\section{Bioavailability}

The question of how, in which chemical form and to what extent phytochemicals gain access to cells and tissues is central to understanding their mode of action. The majority of phytochemicals exist in conjugated form and only a small amount of phytochemicals are present in free form. The modifications (glucuronidation and sulfation by phase II enzymes) lower the bioavailability of the substances by reducing their cell permeability or absorption [59]. Conjugated phytochemicals that are not absorbed in the upper digestive tract may be broken down into smaller molecular weight molecules (for instance cinnamic acid) by the colonic microflora and display a high degree of bioavailability [60]. This aspect of the metabolism of phytochemicals has not been thoroughly investigated and holds a high potential for discovery [61].

It also remains to be investigated whether insoluble metabolites of phytochemicals constitute a spare pool of free active phytochemicals, or only inactive and excretable forms [20]. The influence of the food matrix on the bioavailability of phytochemicals likewise deserves further attention. Flavonoids which are mainly present as glycosides in food (with the exception of catechins) are expected to be poorly absorbed, but quercetin glycosides are absorbed in appreciable amounts in the small intestine [62]. For instance, the flavonoid quercetin was shown to be more bioavailable as an aglycone than quercetin glucosides when ingested as onion flesh, while quercetin glycosides where more available when ingested as dried onion skin [63]. The purified and hydrophobic quercetin aglycone, however, is almost not absorbed. There are also 
contradictory reports as to whether curcumin metabolites are more or less active when conjugated [64].

The maximal concentrations of conjugated and unconjugated resveratrol in the blood can be expected to reach 1-10 $\mu \mathrm{M}$ [65], concentrations at which phytochemicals may exert antiproliferative and apoptosis-promoting effects [18]. Intestinal mucosal cells, however, may be exposed to much higher phytochemical concentrations than those utilized in vitro (up to 100-500 $\mu \mathrm{M}$ ). To induce antioxidant and anticancer effects in vitro, experiments using single phytochemical application always require higher doses than those usually achieved in vivo under physiological conditions. However, the proven in vivo beneficial effects of phytochemicals in cancer prevention and suppression can be explained by additive and synergistic effects, as vegetables and fruits contain multiple different phytochemicals which seem to influence and potentiate each other [59-61]. Synergistic effects increasing the bioavailability are reported. For example quercetin is an inhibitor of resveratrol sulfation in the liver and small intestine and increases the bioavailability of resveratrol [20]. The synergistic effect of piperine on curcumin is driven by its inhibiting effect on curcumin conjugation. Further, absorption of phytochemicals can be enhanced by complexing with lipids or by nanoparticles that increase the water solubility of hydrophobic drugs [64].

\section{Conclusions}

The anticancer effects of phytochemicals manifest themselves both on the cancer cell itself, and on the initiated cell (a cell on its way to become neoplastic). The many pathways that are modified by phytochemicals slow down the inappropriately proliferating cells, most likely by participating in a generic mechanism of cellular regulation which is influenced by the cellular redox state.

As suggested by Stevenson and Hurst [18], humans have had a long time to adjust to the intrinsically noxious effects of plant phytochemicals and consequently have developed adaptive mechanisms to neutralize those phytochemicals. It is quite fascinating to realize that chimpanzees, the evolutionary cousins of man [66], have been shown to make use of plants to try to alleviate ailments $[67,68]$ in a manner analogous to what early humans must have done. Phytochemicals are therefore molecules that have shaped the adaptive and hormetic mechanisms in human physiology and have provided us with the capacity to regulate cellular functions.

The chemopreventive properties of phytochemicals appear sufficient to safely decrease the incidence of cancers due to environmental causes. Whether or not purified phytochemicals could be utilized as drugs to regulate aberrant cellular behaviors will be learned from the many clinical studies presently under way, and, hopefully, selected phytochemicals will find their use in our pharmacology to act in a pleiotropic manner on neoplastic, inflammatory and metabolically unbalanced cells. This could in essence be a new way to influence aberrant cellular behavior, not by seeking the elimination of one faulty molecule (the magic bullet approach), but rather by attempting to reequilibrate an unbalanced cellular machinery, such as in diabetic or cancer cells.

\section{Acknowledgments}

This work was supported by grants from the Swiss National Science Foundation and the Geneva Cancer League (both to D. C.H.).

\section{References}

1 Food, Nutrition, Physical Activity, and the Prevention of Cancer: a Global Perspective. Washington, AICR, 2007.

-2 Aggarwal BB, Shishodia S: Molecular targets of dietary agents for prevention and therapy of cancer. Biochem Pharmacol 2006;71: 1397-1421.

3 Surh YJ: Cancer chemoprevention with dietary phytochemicals. Nat Rev Cancer 2003; 3:768-780.
4 Manson MM: Cancer prevention - the potential for diet to modulate molecular signalling. Trends Mol Med 2003;9:11-18.

5 Ames BN, Profet M, Gold LS: Dietary pesticides (99.99\% natural). Proc Natl Acad Sci USA 1990;87:7777-7781.

6 6 Mattson M, Son T, Camandola S: Viewpoint: mechanisms of action and therapeutic potential of neurohormetic phytochemicals. Dose Response 2007;5:174-186.

7 Son T, Camandola S, Mattson M: Hormetic dietary phytochemicals. Neuromol Med 2008, E-pub ahead of print.
-8 Khanna D, Sethi G, Ahn KS, Pandey MK, Kunnumakkara AB, Sung B, Aggarwal A, Aggarwal BB: Natural products as a gold mine for arthritis treatment. Curr Opin Pharmacol 2007;7:344-351.

-9 Marone R, Cmiljanovic V, Giese B, Wymann MP: Targeting phosphoinositide 3-kinase: moving towards therapy. Biochim Biophys Acta 2008;1784:159-185.

-10 Frojdo S, Cozzone D, Vidal H, Pirola L: Resveratrol is a class IA phosphoinositide 3-kinase inhibitor. Biochem J 2007;406:511-518. 
-11 Akiyama T, Ishida J, Nakagawa S, Ogawara $\mathrm{H}$, Watanabe S, Itoh N, Shibuya M, Fukami Y: Genistein, a specific inhibitor of tyrosinespecific protein kinases. J Biol Chem 1987; 262:5592-5595.

-12 Oliver JM, Burg DL, Wilson BS, McLaughlin $\mathrm{JL}$, Geahlen RL: Inhibition of mast cell $\mathrm{FC}_{\mathrm{C}}$ $\varepsilon$ R1-mediated signaling and effector function by the Syk-selective inhibitor, piceatannol. J Biol Chem 1994;269:29697-29703.

- 13 Kotha A, Sekharam M, Cilenti L, Siddiquee K, Khaled A, Zervos AS, Carter B, Turkson J, Jove R: Resveratrol inhibits Src and Stat3 signaling and induces the apoptosis of malignant cells containing activated Stat 3 protein. Mol Cancer Ther 2006;5:621-629.

14 Pathak AK, Bhutani M, Nair AS, Ahn KS, Chakraborty A, Kadara H, Guha S, Sethi G, Aggarwal BB: Ursolic acid inhibits Stat3 activation pathway leading to suppression of proliferation and chemosensitization of human multiple myeloma cells $10.1158 / 1541$ 7786.Mcr-06-0348. Mol Cancer Res 2007;5: 943-955.

-15 Sharma SV, Gajowniczek P, Way IP, Lee DY, Jiang J, Yuza Y, Classon M, Haber DA, Settlman J: A common signaling cascade may underlie 'addiction' to the Src, BCR-ABL, and EGF receptor oncogenes. Cancer Cell 2006; 10:425-435.

16 Sharma SV, Settleman J: Oncogenic shock Turning an activated kinase against the tumor cell. Cell Cycle 2006;5:2878-2880.

-17 Tauzin S, Ding H, Khatib K, Ahmad I, Burdevet $D$, van Echten-Deckert G, Lindquist JA, Schraven B, Din NU, Borisch B, Hoessli DC: Oncogenic association of the Cbp/PAG adaptor protein with the Lyn tyrosine kinase in human B-NHL rafts. Blood 2008;111: 2310-2320.

18 Stevenson DE, Hurst RD: Polyphenolic phytochemicals: just antioxidants or much more? Cell Mol Life Sci 2007;64:2900-2916.

19 Kundu JK, Surh YJ: Inflammation: gearing the journey to cancer. Mutat Res 2008;659: $15-30$.

20 Baur JA, Sinclair DA: Therapeutic potential of resveratrol: the in vivo evidence. Nat Rev Drug Discov 2006;5:493-506.

-21 Athar M, Back JH, Tang X, Kim KH, Kopelovich L, Bickers DR, Kim AL: Resveratrol: a review of preclinical studies for human cancer prevention. Toxicol Appl Pharmacol 2007;224:274-283.

-22 Andersen OS, Koeppe RE: Bilayer thickness and membrane protein function: an energetic perspective. Annu Rev Biophys Biomol Struct 2007;36:107-130.

-23 Hoessli DC, Ilangumaran S, Soltermann A, Robinson PJ, Borisch B, Nasir-Ud-Din: Signaling through sphingolipid microdomains of the plasma membrane: the concept of signaling platform. Glycoconj J 2000;17:1-7.

-24 Simons K, Toomre D: Lipid rafts and signal transduction. Nat Rev Mol Cell Biol 2000;1: 31-39.
25 Kunwar A, Barik A, Mishra B, Rathinasamy K, Pandey R, Priyadarsini KI: Quantitative cellular uptake, localization and cytotoxicity of curcumin in normal and tumor cells. Biochim Biophys Acta 2008; 1780:673-679.

26 Ingolfsson HI, Koeppe RE, Andersen OS: Curcumin is a modulator of bilayer material properties. Biochemistry 2007;46:1038410391.

27 Hung WC, Chen FY, Lee CC, Sun Y, Lee MT, Huang HW: Membrane-thinning effect of curcumin. Biophys J 2008;94:4331-4338.

28 Lundbaek JA, Birn P, Tape SE, Toombes GES, Sogaard R, Koeppe RE 2nd, Gruner SM, Hansen AJ, Andersen OS: Capsaicin regulates voltage-dependent sodium channels by altering lipid bilayer elasticity. Mol Pharmacol 2005;68:680-689.

29 Hwang TC, Koeppe RE, Andersen OS: Genistein can modulate channel function by a phosphorylation-independent mechanism: importance of hydrophobic mismatch and bilayer mechanics. Biochemistry 2003;42: 13646-13658.

30 Arora A, Byrem T, Nair M, Strasburg G: Modulation of liposomal membrane fluidity by flavonoids and isoflavonoids. Arch Biochem Biophys 2000;373:102-109.

31 Liu A, Pajkovic N, Pang Y, Zhu D, Calamini B, Mesecar AL, van Breemen RB: Absorption and subcellular localization of lycopene in human prostate cancer cells. Mol Cancer Ther 2006;5:2879-2885

32 Tsuchiya H, Nagayama M: Garlic allyl derivatives interact with membrane lipids to modify the membrane fluidity. J Biomed Sci 2008; 15:653-660.

33 Delmas D, Rebe C, Lacour S, Filomenko R, Athias A, Gambert P, Cherkaoui-Malki M, Jannin B, Dubrez-Daloz L, Latruffe N, Solary E: Resveratrol-induced apoptosis is associated with Fas redistribution in the rafts and the formation of a death-inducing signaling complex in colon cancer cells. J Biol Chem 2003;278:41482-41490.

-34 Delmas D, Rébé C, Micheau O, Athias A, Gambert P, Grazide S, Laurent G, Latruffe N, Solary E: Redistribution of CD95, DR4 and DR5 in rafts accounts for the synergistic toxicity of resveratrol and death receptor ligands in colon carcinoma cells. Oncogene 2004;23:8979-8986.

-35 Resh MD: Myristylation and palmitylation of Src family members: the fats of the matter. Cell 1994;76:411-413.

36 Vivanco I, Sawyers CL: The phosphatidylinositol 3-kinase-akt pathway in human cancer. Nat Rev Cancer 2002;2:489-501.

37 Tarahovsky YS, Muzafarov EN, Kim YA: Rafts making and rafts braking: how plant flavonoids may control membrane heterogeneity. Mol Cell Biochem 2008;314:65-71.

38 Chaudhuri S, Banerjee A, Basu K, Sengupta $B$, Sengupta PK: Interaction of flavonoids with red blood cell membrane lipids and proteins: antioxidant and antihemolytic effects. Int J Biol Macromol 2007;41:42-48.
39 García-García J, Micol V, de Godos A, Gómez-Fernández JC: The cancer chemopreventive agent resveratrol is incorporated into model membranes and inhibits protein kinase $\mathrm{C}$ alpha activity. Arch Biochem Biophys 1999;372:382-388

40 Bhardwaj A, Sethi G, Vadhan-Raj S, BuesoRamos C, Takada Y, Gaur U, Nair AS, Shishodia S, Aggarwal BB: Resveratrol inhibits proliferation, induces apoptosis, and overcomes chemoresistance through downregulation of STAT3 and nuclear factor-kappaB-regulated antiapoptotic and cell survival gene products in human multiple myeloma cells. Blood 2007;109:2293-2302.

- 41 Oteiza P, Erlejman A, Verstraeten S, Keen C, Fraga C: Flavonoid-membrane interactions: a protective role of flavonoids at the membrane surface? Clin Dev Immunol 2005;12:19-25.

42 Movileanu L, Neagoe I, Flonta ML: Interaction of the antioxidant flavonoid quercetin with planar lipid bilayers. Int J Pharm 2000; 205:135-146.

-43 Scheidt HA, Pampel A, Nissler L, Gebhardt $\mathrm{R}$, Huster D: Investigation of the membrane localization and distribution of flavonoids by high-resolution magic angle spinning NMR spectroscopy. Biochim Biophys Acta 2004;1663:97-107.

44 Lee JS, Surh YJ: Nrf2 as a novel molecular target for chemoprevention. Cancer Lett 2005;224:171-184.

-45 Surh YJ, Kundu JK, Na HK, Lee JS: Redoxsensitive transcription factors as prime targets for chemoprevention with anti-inflammatory and antioxidative phytochemicals. J Nutr 2005;135:2993S-3001S.

46 Itoh K, Wakabayashi N, Katoh Y, Ishii T, Igarashi K, Engel JD, Yamamoto M: Keap1 represses nuclear activation of antioxidant responsive elements by Nrf2 through binding to the amino-terminal Neh2 domain. Genes Dev 1999;13:76-86.

$47 \mathrm{Na} \mathrm{H}$, Surh Y: Transcriptional regulation via cysteine thiol modification: a novel molecular strategy for chemoprevention and cytoprotection. Mol Carcinog 2006;45:368-380.

48 Banerjee S, Li Y, Wang Z, Sarkar FH: Multitargeted therapy of cancer by genistein. Cancer Lett 2008;269:226-242.

49 Bloom DA, Jaiswal AK: Phosphorylation of $\mathrm{Nrf2}$ at Ser40 by protein kinase $\mathrm{C}$ in response to antioxidants leads to the release of $\mathrm{Nrf2}$ from INrf2, but is not required for Nrf2 stabilization/accumulation in the nucleus and transcriptional activation of antioxidant response element-mediated $\mathrm{NAD}(\mathrm{P}) \mathrm{H}$ :quinone oxidoreductase-1 gene expression. J Biol Chem 2003;278:44675-44682.

50 Keum YS, Yu S, Chang PPJ, Yuan X, Kim JH, $\mathrm{Xu}$ C, Han J, Agarwal A, Kong ANT: Mechanism of action of sulforaphane: inhibition of p38 mitogen-activated protein kinase isoforms contributing to the induction of antioxidant response element-mediated heme oxygenase-1 in human hepatoma Hep-G2 cells. Cancer Res 2006;66:8804-8813. 
-51 Yu R, Chen C, Mo YY, Hebbar V, Owuor ED, Tan TH, Kong ANT: Activation of mitogenactivated protein kinase pathways induces antioxidant response element-mediated gene expression via a Nrf2-dependent mechanism. J Biol Chem 2000;275:39907-39913.

- 52 Traka M, Gasper AV, Melchini A, Bacon JR, Needs PW, Frost V, Chantry A, Jones AME, Ortori CA, Barrett DA, Ball RY, Mills RD, Mithen RF: Broccoli consumption interacts with GSTM1 to perturb oncogenic signalling pathways in the prostate. PLoS ONE 2008;3:e2568.

53 Iijima K, Ohara M, Seki R, Tauchi H: Dancing on damaged DNA: functions of ATM and the RAD50/MRE11/NBS1 complex in cellular responses to DNA damage. J Radiat Res (Tokyo) 2008;49:451-464.

54 Gatz SA, Wiesmuller L: Take a break - resveratrol in action on DNA. Carcinogenesis 2008;29:321-332.

- 55 Jang M, Cai L, Udeani GO, Slowing KV, Thomas CF, Beecher CWW, Fong HHS, Farnsworth NR, Kinghorn AD, Mehta RG, Moon RC, Pezzuto JM: Cancer chemopreventive activity of resveratrol, a natural product derived from grapes. Science 1997; 275:218-220
Alvi N, Rizvi R, Hadi S: Interaction of quercetin with DNA. Biosci Rep 1986;6:861868.

57 Usha S, Johnson I, Malathi R: Interaction of resveratrol and genistein with nucleic acids. J Biochem Mol Biol 2005;38:198-205.

58 Tyagi A, Singh RP, Agarwal C, Siriwardana S, Sclafani RA, Agarwal R: Resveratrol causes Cdc2-tyr15 phosphorylation via ATM/ATR-Chk1/2-CDC25C pathway as a central mechanism for $\mathrm{S}$ phase arrest in human ovarian carcinoma Ovcar-3 cells. Carcinogenesis 2005;26:1978-1987.

59 Williamson G, Barron D, Shimoi K, Terao J: In vitro biological properties of flavonoid conjugates found in vivo. Free Redic Res 2005;39:457-469.

60 Rechner AR, Kuhnle G, Bremner P, Hubbard GP, Moore KP, Rice-Evans CA: The metabolic fate of dietary polyphenols in humans. Free Radic Biol Med 2002;33:220-235.

61 Chu YF, Sun J, Wu X, Liu RH: Antioxidant and antiproliferative activities of common vegetables. J Agric Food Chem 2002;50: 6910-6916.

62 Hollman PCH, Katan MB: Absorption, metabolism and health effects of dietary flavonoids in man. Biomed Pharmacother 1997; 51:305-310.
63 Wiczkowski W, Romaszko J, Bucinski A, Szawara-Nowak D, Honke J, Zielinski $\mathrm{H}$, Piskula MK: Quercetin from shallots (Allium cepa L. var. aggregatum) is more bioavailable than its glucosides. J Nutr 2008; 138: 885-888.

-64 Anand P, Kunnumakkara AB, Newman RA Aggarwal BB: Bioavailability of curcumin: problems and promises. Mol Pharm 2007;4: 807-818.

65 Kroon PA, Clifford MN, Crozier A, Day AJ, Donovan JL, Manach C, Williamson G: How should we assess the effects of exposure to dietary polyphenols in vitro? Am J Clin Nutr 2004;80:15-21.

66 Diamond J: The Third Chimpanzee. New York, Harper Perennial, 1992.

67 Huffman M: Animal self-medication and ethno-medicine: exploration and exploitation of the medicinal properties of plants. Proc Nutr Soc 2003;62:371-381.

68 Krief S, Hladik CM, Haxaire C: Ethnomedicinal and bioactive properties of plants ingested by wild chimpanzees in Uganda. J Ethnopharmacol 2005;101:1-15. 